\title{
Team-Based Learning in Medical Ethics Education: Evaluation and Preferences of Students in Oman
}

\author{
Miriam Simon ${ }^{1, *}$ \\ ${ }^{1}$ Department of Psychiatry and Behavioral Science, College of Medicine and Health Sciences, National University of Science and Technology, Sohar, Sultanate of Oman \\ "Corresponding author: Department of Psychiatry and Behavioral Science, College of Medicine and Health Sciences, National University of Science and Technology, Sohar, \\ Sultanate of Oman. Email: miriam@omc.edu.om
}

Received 2020 June 10; Revised 2020 October 24; Accepted 2020 November 10.

\begin{abstract}
Objectives: The purpose of this study was to explore the impact of integrating team-based learning sessions in undergraduate medical ethics education. Though used effectively in other pre-clinical courses, team-based learning is not frequently used in medical ethics education. Student's accountability for learning, preference for team-based learning, and satisfaction were studied.

Methods: Three team-based learning sessions covering focal topics in medical ethics was introduced in the pre-clinical Health Care Ethics course for students at the College of Medicine and Health Sciences, National University of Science and Technology. On the completion of three modules, the team-based learning student assessment instrument (TBL-SAI) by Heidi Mennenga was used to evaluate student perceptions. To this aim, 118 students who had registered for the Health Care Ethics course completed the survey. Results: The findings indicated that students reported a positive experience of team-based learning in medical ethics education. Students also indicated high accountability for their learning, a high preference for team-based learning to lectures in the medical ethics course, and high satisfaction.

Conclusions: Team-based learning is thus preferred by students to cover topics and courses in medical ethics. Integrating teambased modules in medical ethics education will enhance self-directed learning, improve teamwork, and help students effectively recall and apply information. It is therefore recommended to integrate team-based learning sessions in medical ethics education.
\end{abstract}

Keywords: Medical Ethics Education, Team-Based Learning

\section{Background}

Team-based learning(TBL) generates an active learning environment in the classroom. This method is a learnercentered, instructor-directed strategy that incorporates class-based teamwork and assessment to enhance active learning and critical thinking (1). A meta-analysis on the effectiveness of TBL reports an improvement in students' grades and classroom engagement. A deeper understanding of content was also reported by students following TBL sessions (2).

Initially formulated by Michaelsen in 1979 (cited in Haque and Md), Team-based learning was effectively introduced into medical education in the late 1990s (3). Currently, a lot of medical schools globally have integrated TBL into curriculum delivery as a more popular and preferred method to lecture-based learning (4). Though relatively new to healthcare education, TBL also provides a more innovative approach to student-centered learning in comparison to the commonly used problem-based learning (5). The advantage of TBL is that it does not require a large number of tutors while maintaining the positive experience of small group teaching and learning (6). A systematic review of published literature in the area of health professions education indicated that the number of articles on TBL had tripled between 2011 and 2016, mostly involving undergraduate medical education (7). TBL, as part of a blended learning environment, is shown to increase the level of student engagement (8), improve knowledgebased performance, and stimulate long-term retention of information (9). Research also indicates that students' attitudes about teamwork, their sense of professional development, and acceptance of peer evaluation improved after using team-based learning in the curriculum (10).

The openness of medical students for this learning strategy most often indicates a positive preference. Though most students reported that they had to prepare before TBL sessions, they believed the method was an effective approach as it helped with better recall of information and improvement in grades. They also reported a preference for TBL over traditional lectures (11). TBL was viewed 
by medical students as a more effective opportunity to cultivate critical reasoning and clinical problem-solving skills when compared to other non-lecture, active methods of teaching and learning like labs or case discussions. It also allowed for enhanced learning of core concepts through student to student interaction (12).

Though medical ethics in undergraduate education is a vital component, teaching the subject (in terms of ensuring student interest and participation) has always been challenging as the focus for students will be their core medical courses. The other challenges faced by faculty members include a perceived lack of value or relevance by students and inadequate teaching methods. When compared to the conventional lecture method, studies have shown that the integration of TBL in medical ethics modules improved student performance and increased student engagement and satisfaction (13). Though not widely used in medical ethics education, TBL was also found superior to lectures at long-term retention tests (14). But when employed, TBL sessions in medical ethics are very well-received by students (15).

In the Middle Eastern Region, TBL has been effectively employed in teaching anatomy (16), physiology (17), pharmacology (18), and other pre-clinical subjects (19). Problem-based learning or small group discussions have been preferred for topics in medical ethics (20). In undergraduate medical education in the Sultanate of Oman, TBL has been used for courses in basic sciences (21) and anatomy (22). There is no literature on TBL being used in medical ethics courses. A study conducted at the College of Medicine and Health Sciences (erstwhile Oman Medical College), National University of Science and Technology, (COMHS, NUST) Sultanate of Oman concluded that faculty members are interested in employing active teachinglearning strategies for their courses, but were unable to do so due to the lack of necessary class time, high comfort level with traditional lectures and paucity of time to develop materials (23).

As a part of professional development, faculty members in the College of Medicine and Health Sciences were trained to employ TBL in the interest of enhancing active teaching-learning strategies in the classroom, sustain student engagement across various courses and improve selfdirected learning and analytical thinking among students. The author, therefore, designed and integrated TBL modules to the pre-clinical course in health care ethics. The impact of these modules on student's satisfaction, preference regarding the teaching-learning strategy, and accountability to learn was explored.

\section{Objectives}

The purpose of this study was to explore the effectiveness of TBL in medical ethics education. This is one of the first initiatives of employing TBL in medical ethics education in the Middle Eastern Region.

\section{Methods}

\subsection{Research Design}

The cross-sectional research design was used in this study. The Team-based learning student assessment instrument (TBL-SAI) was used to evaluate student perceptions of TBL modules in medical ethics education. Approval from the institution's Ethics and Biosafety Committee was obtained. Data were collected using the survey method.

\subsection{Participants}

The Health Care Ethics course is offered during the second year of pre-clinical training (MD4) at the COMHS, NUST. One hundred eighteen students of the MD4 cohort had registered for the course during the academic year 2019. This course was offered as a blended program, including lectures and TBL modules. In addition to lectures, three TBL modules were designed by the author (who was the course director) to be integrated into the Health Care Ethics course.

All 118 students attended both lectures and TBL modules. The cohort of 118 students was divided into three batches, including batch A, batch B, and batch C. Each batch had around 39 to 40 students. Each batch was then further divided into ten teams. Each team thus had around 4 students. The same format was implemented for all batches while implementing TBL sessions. A random sampling method was used. All 118 students from the cohort participated in the study.

\subsection{Procedure}

The learning resource used for the TBL modules was the BMA Ethics Toolkit (24). The content covered in the three TBL modules included the following focal topics:

A) Autonomy or Self- determination;

B) Consent to the treatment. Adults who lack capacity, Children and Young people;

C) Communication and Confidentiality.

Figure 1 illustrates the steps that were followed in the implementation of each TBL session:

1) Preparation: Students were informed of the assigned pre-reading material at least one week before the scheduled TBL session. Content/learning cards from the BMA Ethics toolkit were used as pre-reading material. 
Preparation Assessment Feedback Application Discussion

Figure 1. Steps in TBL implementation

2) Assessment: During the scheduled TBL session, students were administered the Individual Readiness Assurance test (IRAT). Question formats included multiplechoice questions (single response), one-word questions, and short answer questions. Students then completed the Team Readiness Assurance test (TRAT) in the groups allotted to them.

3) Feedback: Once the TRAT was completed, the course director discussed the test items in the assessment. Opportunity for appeals was also provided.

4) Application: Students were then given an application exercise to be done in teams. The exercise was to solve a case with an ethical dilemma. Cases were designed to correspond to the focal topic for specific sessions. A case template based on the "seven-step protocol to solve cases with ethical dilemmas" (25) was used to aid students with case analysis. The steps in the template included:

A) What are the ethical questions?

B) What are the clinically relevant facts?

C) What are the ethical values at stake?

D) List options.

E) What will you do?

F) Justify your choice.

G) How could this ethical issue have been prevented?

H) Contextualization to Oman

5) Discussion: Group discussion was initiated, and the cases were analyzed.

\subsection{Study Instrument}

Students were asked to complete the TBL-SAI on the completion of the three TBL sessions. The 33-item TBL-SAI developed by Mennenga in 2010 evaluates students' experiences in team-based learning and has been established to be a valid and reliable tool. A content validity index of 0.89 has been reported. Internal consistency for the three subscales: Accountability, preference for the lecture, or TBL, and student satisfaction has also been established (26). The TBL-SAI employs a Likert scale. Each item is scored on a scale from one to five ( $1=$ "strongly disagree", 2 = "disagree", 3 = "neither disagree or agree", 4 = "agree", and 5 = "strongly agree"). The scale allows participants to opt for a neutral response. The Accountability subscale is composed of eight items, and scores range from 8 - 40, Preference for lecture or TBL subscale contains 16 items, and scores range from 16 - 80 and the student satisfaction subscale comprises nine items and scores range from 9 - 45. The total score of the TBL-SAI ranges from 33 - 165. Neutral scores were defined by the author for the three sub-scales: accountability: 24 ; preference for lecture or TBL: 48; student satisfaction: 27; and total score: 99. Positive attitudes or experiences are classified as scores that are higher than the neutral scores (27).

\subsection{Statistical Analysis}

Students were asked to complete the TBL-SAI on the secure learning online environment (SOLE), the institutional online learning portal. Their responses were anonymous. The results were then analyzed using IBM's SPSS version 25 (28). Descriptive statistical methods were used to analyze data.

\section{Results}

The survey results from 118 students in the MD4 preclinical cohort were obtained and analyzed. The average age of participants was 21.5 years. All students were in the second year of pre-clinical training.

The results indicated that the mean score of participants on the TBL-SAI was 116.85 (SD =10.99). The mean score is higher than the neutral score of 99 as established by Mennenga, indicating that the students had a positive experience during the TBL modules in Health Care Ethics. The distribution of scores is seen in Figure 2.

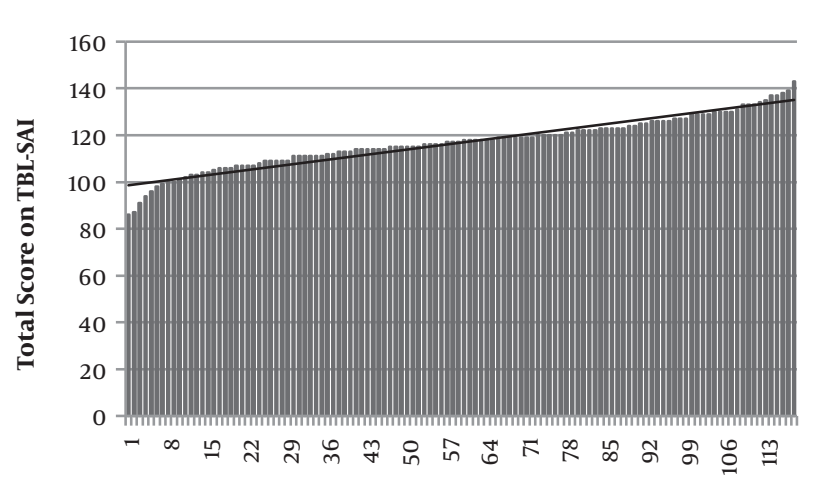

Figure 2. Total scores obtained from TBL-SAI

The results on the Accountability subscale portray students' preparation for the TBL session and contribution to the team. The mean score on this subscale was 31.2 (SD $=4.28$ ). The mean is higher than the neutral score of 24 as suggested by Mennenga, indicating that participants exhibited high accountability towards their learning and that of their team as seen in Figure 3. 


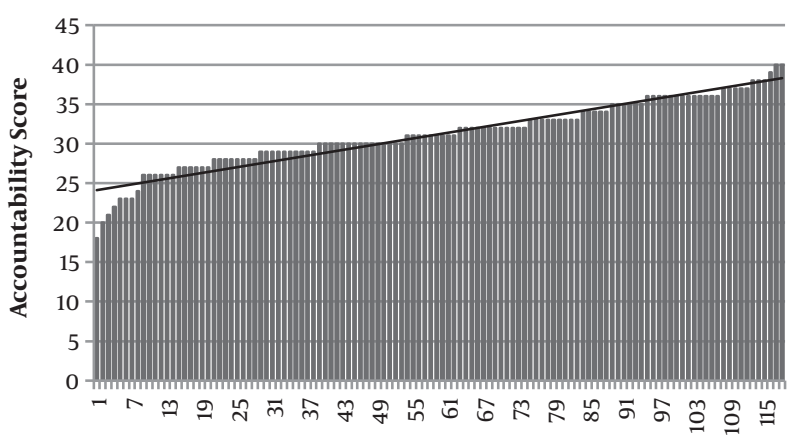

Figure 3. Scores obtained from Accountability subscale

The majority of students indicated that they spent time studying ahead of the class in order to be more prepared (69.49\%), that they contributed towards their team's learning (88.14\%), and that they were proud to assist their team in learning (73.73\%).

The second subscale involved preference for lectures and team-based learning. Scores reported the student's ability to recall material and their attention level during lectures and team-based learning. The participant's mean score on this subscale was $52.1(\mathrm{SD}=3.88)$. When compared to the neutral score of 48 , the mean score indicated that the students preferred TBL to lectures in Health Care Ethics. The distribution of scores is shown in Figure 4.

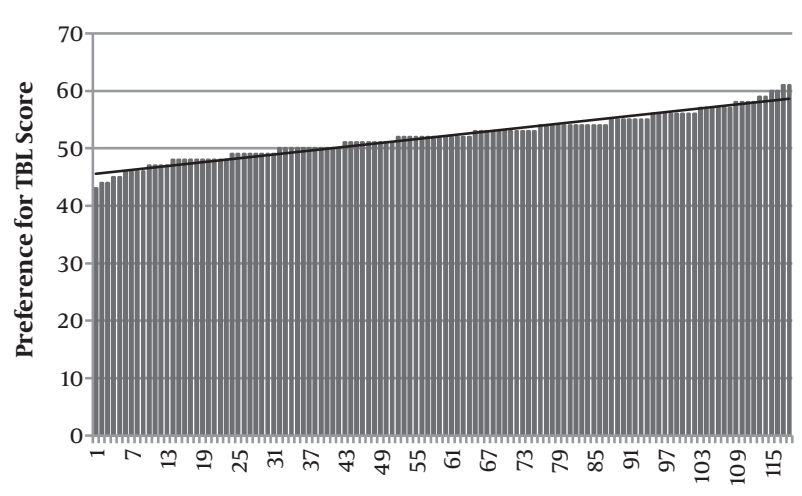

Figure 4. Scores on preference for TBL subscale

The majority of the participants indicated that, compared to lectures, distraction (66.1\%), boredom (50.85\%) and tendency to be sleepy (66.1\%) were lower during TBL sessions. The results also indicated that the students felt they remembered information better when learned during a TBL (75.42\%) that the application exercise aided the process of recall (80.51\%) and they would do better in exams if the content was covered using TBL (62.71\%).
The third subscale assesses student satisfaction with TBL. The participants' mean score on this subscale was 33.54 ( $\mathrm{SD}=5.62)$. The neutral score for this subscale suggested by Mennenga is 27. The mean score indicates that students showed high satisfaction for TBL in medical ethics education, as seen in Figure 5.

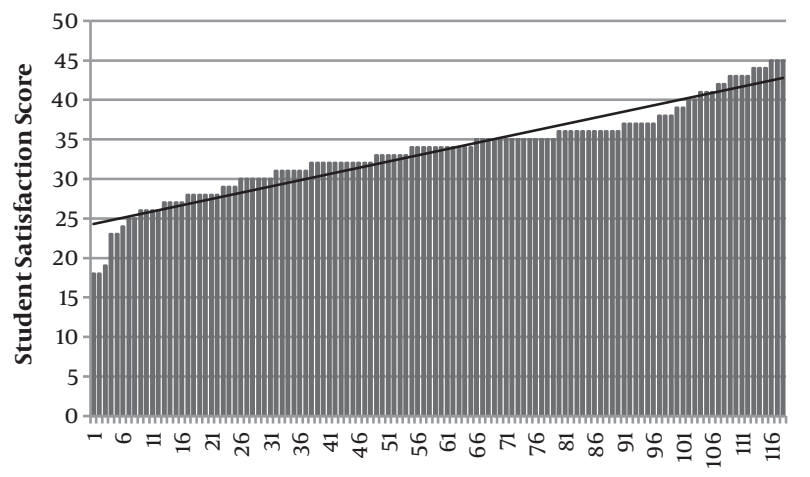

Figure 5. Scores on student satisfaction subscale

The students indicated that they enjoyed TBL activities (69.95\%), that they learned better in a team setting (65.26\%), and understood the subject better (66.1\%). They also reported that TBL activities in medical ethics are an effective approach to learning (71.18\%) and that they had a positive attitude (70.33\%) and a good experience (77.12\%).

\section{Discussion}

Overall, the results indicate that students had a positive experience with TBL during their health care ethics course. Accountability, preference for TBL, and student satisfaction were also high.

The integration of TBL in health care ethics education has positively impacted the transfer of knowledge to students while enhancing independence and responsibility with regard to learning, especially self-directed learning. Self-directed learning is described as a process in which individuals take the initiative in diagnosing learning needs, formulating goals, identifying resources, and evaluating learning outcomes (29). The TBL process followed in this study ensured that students took responsibility for their own learning and hence enhanced the skills of being a lifelong learner, a core competency for any medical student (30).

It was also observed among the students who participated in this study that self-directed learning coupled with the opportunity to exhibit knowledge and rewarded with external appreciation and gratitude improved student engagement in the course and may in turn positively rein- 
force future learning as well. The effectiveness of constructivism (31) and reinforcement in medical education is substantiated. This cycle illustrates the process of this study (Figure 6).

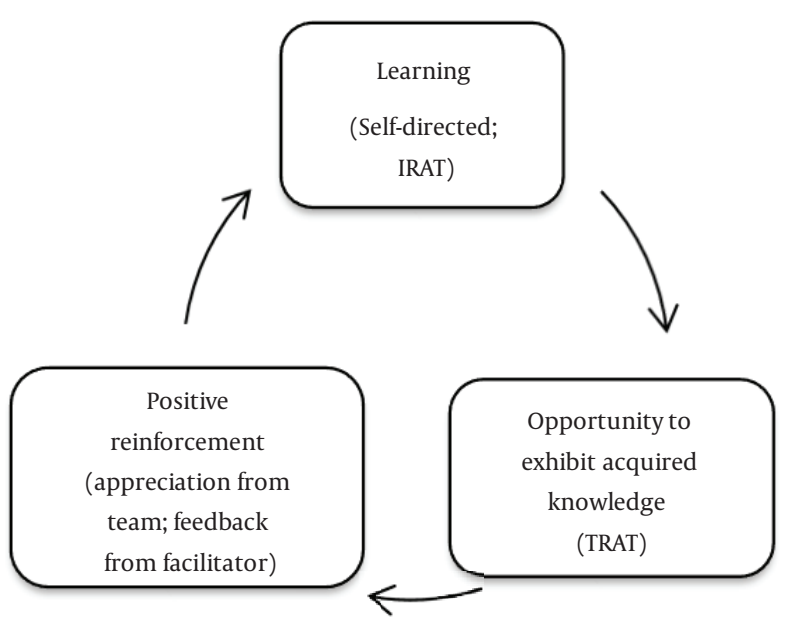

Figure 6. Cycle of reinforcement seen in TBL

The students clearly had a positive preference for TBL over lectures for the health care ethics course. Discussing and debating ethical scenarios as teams helped in the understanding of concepts, familiarized students with technical terms to be used, and improved analytical thinking. Interpersonal interaction and communication among team members also ensured that interest was sustained in medical ethics education.

\subsection{Conclusions and Implications}

Though TBL is not widely used in medical ethics education, the results of the present study indicate that integrating TBL modules will be effective in student learning and invaluable in helping them understand and, later in their career, apply concepts to practice. The common challenges for faculty in planning TBL sessions for medical ethics courses usually are low credit hours for the course, low priority for the subject, the lack of preparation time, and non-availability of staff support to conduct TBL sessions. In most institutions, medical ethics topics are usually covered as a series of lectures or a one-day seminar.

Implementing TBL sessions for the health care ethics course in the COMHS, NUST has indicated that positive experience and improved learning for students. The impact of TBL in increasing self-directed learning, teamwork, understanding and recalling information, application of concepts, and providing a favorable learning environment also indicates the enhanced interest toward subject-medical ethics. It is recommended that TBL modules should be considered in medical ethics education in the interest of student learning, academic enhancement and overall professional training.

\section{Acknowledgments}

The author thanks Heidi A. Mennenga, PhD, RN for granting permission to utilize the TBL-SAI and providing scoring support.

\section{Footnotes}

Authors' Contribution: The author is the sole author of the manuscript and has independently carried out the study.

Conflict of Interests: None.

Ethical Approval: Ethical approval was obtained from the institution's Ethics and Bio-Safety Committee.

Funding/Support: None.

Informed Consent: Only student course feedback is reported in this study.

\section{References}

1. Parmelee D, Michaelsen LK, Cook S, Hudes PD. Team-based learning: a practical guide: AMEE guide no. 65. Med Teach. 2012;34(5):e275-87. doi: 10.3109/0142159X.2012.651179. [PubMed: 22471941].

2. Swanson E, McCulley LV, Osman DJ, Scammacca Lewis N, Solis M. The effect of team-based learning on content knowledge: A meta-analysis. Active Learn Higher Educ. 2017;20(1):39-50. doi: $10.1177 / 1469787417731201$.

3. Haque MM, Md A. Team Based Learning in Medical Education - A Review. Int J Pharm Sci Rev Res. 2017;43:59-63.

4. Chen M, Ni C, Hu Y, Wang M, Liu L, Ji X, et al. Meta-analysis on the effectiveness of team-based learning on medical education in China. BMC Med Educ. 2018;18(1):77. doi: 10.1186/s12909-018-1179-1. [PubMed: 29636039]. [PubMed Central: PMC5894173].

5. Burgess A, Mellis C. Team-Based Learning in Health Care Education: Maintaining Key Design Elements. J Nurs Care. 2015;s1. doi: 10.4172/2167-1168.s1-008.

6. Burgess A, Bleasel J, Haq I, Roberts C, Garsia R, Robertson T, et al. Teambased learning (TBL) in the medical curriculum: better than PBL? BMC Med Educ. 2017;17(1):243. doi: 10.1186/s12909-017-1068-z. [PubMed: 29221459]. [PubMed Central: PMC5723088].

7. Reimschisel T, Herring AL, Huang J, Minor TJ. A systematic review of the published literature on team-based learning in health professions education. Med Teach. 2017;39(12):1227-37. doi: 10.1080/0142159X.2017.1340636. [PubMed: 28664760].

8. Faezi ST, Moradi K, Ghafar Rahimi Amin A, Akhlaghi M, Keshmiri F. The effects of team-based learning on learning outcomes in a course of rheumatology.JAdv Med Educ Prof. 2018;6(1):22-30. [PubMed: 29344526]. [PubMed Central: PMC5757153].

9. Cevik AA, ElZubeir M, Abu-Zidan FM, Shaban S. Team-based learning improves knowledge and retention in an emergency medicine clerkship. Int J Emerg Med. 2019;12(1):6. doi: 10.1186/s12245-019-0222-2. [PubMed: 31179926]. [PubMed Central: PMC6371557]. 
10. Parmelee DX, DeStephen D, Borges NJ. Medical students' attitudes about team-based learning in a pre-clinical curriculum. Med Educ Online. 2009;14:1. doi: 10.3885/meo.2009.Res00280. [PubMed: 20165515]. [PubMed Central: PMC2779620].

11. Kazory A, Zaidi Z. Team-Based Learning Activities for First-Year Medical Students: Perception of the Learners. South Med J. 2018;111(9):525-9. doi: 10.14423/SMJ.0000000000000865. [PubMed: 30180247].

12. Deardorff AS, Moore JA, Borges NJ, Parmelee DX. Assessing first year medical student attitudes of effectiveness of team-based learning. Med Sci Educ. 2010;20(2):67-72.

13. Chung EK, Rhee JA, Baik YH, A OS. The effect of team-based learning in medical ethics education. Med Teach. 2009;31(11):1013-7. doi: 10.3109/01421590802590553. [PubMed: 19909042].

14. Ozgonul L, Alimoglu MK. Comparison of lecture and team-based learning in medical ethics education. Nurs Ethics. 2019;26(3):903-13. doi: 10.1177/0969733017731916. [PubMed: 28946799].

15. Gaffney MM, Cottingham AH. Four Medical Ethics Team-Based Learning Modules. MedEdPORTAL. 2012;8(1). doi: 10.15766/mep_23748265.9268.

16. Ghorbani N, Karbalay-Doust S, Noorafshan A. Is a Team-based Learning Approach to Anatomy Teaching Superior to Didactic Lecturing? Sultan Qaboos Univ Med J. 2014;14(1):e120-5. doi: 10.12816/0003345. [PubMed: 24516741]. [PubMed Central: PMC3916264].

17. Obad AS, Peeran AA, Shareef MA, Alsheikh WJ, Kalagi DA, AlAmodi AA, et al. Assessment of first-year medical students' perceptions of teaching and learning through team-based learning sessions. Adv Physiol Educ. 2016;40(4):536-42. doi: 10.1152/advan.00001.2016. [PubMed: 27836858].

18. Bengü E. Application of Team-Based Learning at a Health Science Course: A Case Study. Athens JEduc. 2019;6(1):77-91. doi: 10.30958/aje.61-5.

19. Naggar M, Almaeen A, Alduraywish A. Medical Students' Accountability, Preferences and Satisfaction with Team- Based Learning. Majmaah J Health Sci. 2019;7(2). doi: 10.5455/mjhs.2019.01.007.

20. Heidari A, Adeli SH, Taziki SA, Akbari V, Ghadir MR, MoosaviMovahhed SM, et al. Teaching medical ethics: problem-based learning or small group discussion? J Med Ethics Hist Med. 2013;6:1. [PubMed: 23908762]. [PubMed Central: PMC3713927].

21. Inuwa IM, Al-Rawahy M, Roychoudhry S, Taranikanti V. Implementing a modified team-based learning strategy in the first phase of an outcome-based curriculum-challenges and prospects. Med Teach.2012;34(7):e492-9. doi:10.3109/0142159X.2012.668633. [PubMed: 22746967].

22. Inuwa IM. Perceptions and Attitudes of First-Year Medical Students on a Modified Team-Based Learning (TBL) Strategy in Anatomy. Sultan Qaboos Univ Med J. 2012;12(3):336-43. doi: 10.12816/0003148. [PubMed: 22912927]. [PubMed Central: PMC3413625].

23. Jahan F, Siddiqui M, AlKhouri M, Ahuja A, AlWard M. Active Teaching and Learning Strategies in Medical Education: Perception and Barriers among Faculty Members at Oman Medical College,Sohar/Bowshar Sultanate of Oman. Turkish J Fam Med Primary Care. 2016;10(1). doi: 10.5455/tjfmpc.198970.

24. Ethical guidance for medical students toolkit - BMA. The British Medical Association is the trade union and professional body for doctors in the UK. 2020, [cited 2020 May 9]. Available from: https://www.bma.org.uk/advice-and-support/ethics/medicalstudents/ethics-toolkit-for-medical-students.

25. Lo B. Resolving ethical dilemmas: a guide for clinicians. Lippincott Williams \& Wilkins; 2013.

26. Mennenga HA. Development and psychometric testing of the Team-Based Learning Student Assessment Instrument. Nurse Educ. 2012;37(4):168-72. doi: 10.1097/NNE.0b013e31825a87cc. [PubMed: 22688878].

27. Livingston B, Lundy M, Harrington S. Physical therapy students' perceptions of team-based learning in gross anatomy using the Team-Based Learning Student Assessment Instrument. J Educ Eval Health Prof. 2014;11:1. doi:10.3352/jeehp.2014.11.1. [PubMed: 24699446]. [PubMed Central: PMC3977364].

28. Ibm CR. IBM SPSS Statistics for Windows, Version Q3 25.0. Armonk, NY: BM Corporation; 2017.

29. Manning G. Self-directed learning: A key component of adult learning theory. Bus Public Admin Stud. 2007;2(2):104.

30. Marzo RR. Role of Medical Education in Cultivating Lifelong Learning Skills for Future Doctors. Educ Med J. 2018;10(3):63-6. doi: 10.21315/eimj2018.10.3.7.

31. Dennick R. Constructivism: reflections on twenty five years teaching the constructivist approach in medical education. Int $\mathrm{J}$ Med Educ. 2016;7:200-5. doi: 10.5116/ijme.5763.de11. [PubMed: 27344115]. [PubMed Central: PMC4939219]. 